\title{
The Home Screen Media Environment of Saudi Toddlers
}

\author{
Haifa Alroqi ${ }^{1,2}$, Ludovica Serratrice $^{3}$, Thea Cameron-Faulkner ${ }^{1}$
}

${ }^{1}$ School of Arts, Languages and Cultures, University of Manchester, UK

${ }^{2}$ Department of European Languages and Literature, King Abdulaziz University, Saudi Arabia

${ }^{3}$ School of Psychology and Clinical Language Sciences, University of Reading, UK

Corresponding author: Haifa Alroqi, School of Arts, Languages and Cultures, University of Manchester, UK. Email: halroqi@ kau.edu.sa

Funding: This work was part of a PhD scholarship supported by King Abdulaziz University, Jeddah, Saudi Arabia.

Financial Disclosure: The authors have no financial relationships relevant to this article to disclose.

Conflict of Interest: The authors have no conflicts of interest relevant to this article to disclose.

This is a preprint of an article that has been accepted for publication in the Journal of Children and Media, published by Taylor \& Francis. When the article appears in print, it can be accessed at the following URL: https://doi.org/10.1080/17482798.2021.1921819 


\begin{abstract}
The past few years have witnessed a rapid increase in the use of screen media by adults and children alike. Despite the widespread use of technology in Saudi Arabia, previous findings on Saudi children's screen media use have been inconsistent and contradictory. The current study provides a comprehensive picture of screen media use among young children in Saudi Arabia. It explored the home screen media environment of 220 children aged 1 to 3 years, whose primary caregivers completed an online survey. Findings showed that the vast majority of these children had started using screens before the age of 2 years. On average, Saudi toddlers watched television for about 2 hours a day and used mobile media devices for about 1 hour a day. Their overall screen time was about 3 hours a day. Results also indicated that media use rates among Saudi toddlers are higher than those reported in the United States and the United Kingdom. The most viewed content genre on mobile media was children's songs. Understanding children's patterns of media use is an important first step in guiding the development of research-driven recommendations for all stakeholders on the use of screen media by young children.
\end{abstract}

Keywords: children, media use, mobile media, screen time, technology, toddlers, screens 
The first three years of life are of critical importance for the development of the brain, language abilities, and cognitive skills (Bornstein, 2015; Bradley et al., 1989; Rodriguez et al., 2009; Stiles, 2000). Research indicates that children's home literacy environments (HLE), particularly within the first few years of life, are robust predictors of early linguistic and cognitive development (e.g., Griffin \& Morrison, 1997; Liebeskind, Piotrowski, Lapierre, \& Linebarger, 2014; Payne, Whitehurst, \& Angell, 1994; Rodriguez et al., 2009). Screen media, which can refer to any type of visual content viewed from a screen of any device, including traditional media devices (e.g., television) and new media devices (e.g., mobile media or touchscreens), have become an integral part of everyday life and an important component of the HLE of young children (Lavigne, Hanson, \& Anderson, 2015; Liebeskind et al., 2014, Piotrowski, 2017; Rideout, 2017). The last few years have witnessed a phenomenal growth in media technology. Yet, scientific research and policy statements on children's screen media use lag behind the pace of digital innovation (Kabali et al., 2015; Lauricella, Blackwell, \& Wartella, 2017; Lovato \& Waxman, 2016).

The latest guidelines from the American Academy of Pediatrics (American Academy of Pediatrics, 2016) recommend zero screen time for children under the age of 2 and no more than 1 hour per day of high-quality programming for children aged 2 to 5 years. In numerous policy statements, the AAP has warned about problems associated with excessive screen media use, including obesity, sleep issues, aggressive behaviour, lower academic achievement, and language delays (American Academy of Pediatrics, 2011, 2013, 2016). Several international health bodies also recommend limiting screen time for children under 5 years old (e.g., Australian Department of Health, 2017; Canadian Paediatric Society, 2017; German Federal Ministry of Health, 2016). 
Previous research has shown that several aspects of screen media use among children (e.g., quantity, content, context, onset age, ownership, and accessibility) are associated with developmental (including cognitive and language) outcomes in children. In particular, younger children (under 2 years) may experience greater negative effects from screen media than older children (above 2 years; e.g., Anderson \& Pempek, 2005; Chonchaiya \& Pruksananonda, 2008; Roseberry, Hirsh-Pasek, Parish-Morris, \& Golinkoff, 2009).

A major concern is that screen media use may displace time young children spend in other stimulating activities such as shared reading (e.g., Anderson \& Subrahmanyam, 2017; Christakis, 2014; Hofferth, 2010; Seo \& Lee, 2017; Tomopoulos et al., 2007). Shared reading is one of the most important HLE components that are positively linked with concurrent and longterm literacy and language outcomes (e.g., Farrant \& Zubrick, 2011; Evans, Shaw, \& Bell, 2000; Ninio, 1983; Payne et al., 1994; Whitehurst \& Lonigan, 1998).

Saudi Arabia is the largest media market in the Middle East and North Africa (MENA) region, contributing to almost a third of its revenues (Dubai Press Club \& Dubai Media City, 2016). Despite the increasingly prevalent use of mobile media in Saudi Arabia (Dubai Press Club \& Dubai Media City, 2016; Northwestern University in Qatar, 2017), Saudi organisations and societies fall short of providing data or giving guidelines and recommendations on screen media use for all ages, including children. Furthermore, most of the data available about Saudis' use of screen media are in the form of market research reports, press releases, or summaries of unpublished survey results that primarily focus on the screen media practices of adult users.

Previous research findings on the amount of Saudi children's screen time have been inconsistent and contradictory. Al-Agha, Nizar, and Nahhas (2016) found that the majority of 2to 18 -year-olds in their sample spent 2 hours or more watching television and 2 hours or more 
using mobile media, daily. They did not, however, provide exact information on the average amount of time in minutes or hours that children spent with screen media. In another investigation, the Saudi National Center for Public Opinion Polls (2017a) found that the vast majority (91\%) of Saudi children in their sample used mobile media and electronic games. According to their data, the average amount of time children spent on using smart devices and electronic games was 4 hours per day (Saudi National Center for Public Opinion Polls, 2017a). More than half of the children in the poll reported spending 2 to 5 hours a day using smart devices and electronic games, whilst one in four children noted spending more than 5 hours a day with mobile media and electronic games. However, the only available information on this investigation was a short summary that did not report the ages of the children in the sample and did not provide information on children's television viewing time.

A scant number of studies provide some data on other aspects of children's screen media exposure in Saudi Arabia, including accessibility of screens in children's households, the onset age of consuming screen media, and the genre of screen media content. Reports indicate that TV still dominates children's screen media exposure in the Middle East (Turner Broadcasting System International, 2016). About half of Saudi children started using smart devices and electronic games before the age of five (Saudi National Center for Public Opinion Polls, 2017a). In addition, it has been shown that entertainment screen media content is more popular among Saudi children than educational content (Saudi National Center for Public Opinion Polls, 2017a).

Despite the research noted above, there remain significant gaps in the literature and in our understanding of media usage patterns among children across the world, as well as in the MENA region and in Saudi Arabia in particular. Globally, research on digital media is at an early stage, and much of what is known in this area is informed by studies on older children and adolescents 
(Przybylski \& Weinstein, 2017). In the MENA region, the few studies that have dealt with children's media use report inconsistent findings on the quantity of screen media use and do not address its content or context.

Research on children under the age of 3 in Saudi Arabia has often been a neglected area in child development research. The importance of conducting research on this young population is further emphasised in Saudi Arabia, a demographically young country, where almost $40 \%$ of the population is under the age of 20 , with $10 \%$ under the age of 4 years, constituting the largest age group in the population (Saudi General Authority for Statistics, 2016). Additional research is further necessitated in the country due to its rapidly increasing access to diverse media platforms (Dubai Press Club \& Dubai Media City, 2016; Northwestern University in Qatar, 2017) and its ambitious 2030 Vision, which calls for investing in early childhood care and education (Saudi Council of Economic and Development Affairs, 2016).

The current study is the first of two studies that collectively address Saudi toddlers' (1- to 3-year-olds) screen media practices, parental attitudes towards their children's screen media use, and parental media mediation styles. In this study, screen media refers to any type of visual content viewed or played on a screen of any device, including TV sets, DVD players, computers, video game players, game consoles, smartphones, tablets, or other digital devices (Rideout, 2017). Mobile media refers to handheld devices such as smartphones, tablets, and similar devices that can connect to the Internet, display videos, and download apps (Rideout, 2017).

In order to provide a better understanding of the home screen media environment of Saudi toddlers, we addressed the following questions:

1. How prevalent is access to screen media in Saudi toddlers' homes?

2. How early in life do Saudi children start to view/use screen media? 
3. How much time do Saudi toddlers spend consuming screen media?

4. How prevalent are screen media, compared to reading, among Saudi toddlers?

5. What are Saudi toddlers' most viewed mobile media content types?

6. How do screen media practices among Saudi children compare to those reported in the U.S. and the UK?

\section{Methods}

\section{Participants}

The final sample in the present study consisted of 220 primary caregivers of 1 - to 3-yearold Saudi children residing in Saudi Arabia. Between April and June of 2016, caregivers of Saudi children aged 1 to 3 years old were recruited via several social media platforms and invited to complete an anonymous online survey (see Appendix A) via an embedded URL. Six hundred and fifteen potential respondents started completing the survey. Four hundred and twenty-two completed the entire survey. The dropout attrition rate was about $31 \%$. Out of the 422 completed surveys, 202 were eliminated for one or more of the following reasons: (a) the child was younger than 1 year or older than 3 years $(n=134)$, (b) the child was not a Saudi citizen or was not a resident of Saudi Arabia $(n=31)$, or (c) the child had health or developmental issues that may interfere with her/his media environment (e.g., autism, hearing impairment, neurological disorder; $n=37$ ).

The mean age of the children in the study was 25.34 months $(S D=6.73)$, and they were evenly split between females and males (49\% and 51\%, respectively). The vast majority of the respondents in the study were the target children's mothers (99\%). The term target child is used to refer to the toddler in the household who was reported on for this study by the survey 
respondent. The survey gathered demographic information on both parents. Tables 1 and 2 provide details of the sample characteristics.

Table 1

Socioeconomic Characteristics of the Parents

\begin{tabular}{|c|c|c|c|c|}
\hline \multirow{2}{*}{ Parental SES variable } & \multicolumn{2}{|c|}{ Mothers } & \multicolumn{2}{|c|}{ Fathers } \\
\hline & $n$ & $\%$ & $n$ & $\%$ \\
\hline \multicolumn{5}{|l|}{ Age } \\
\hline$\leq 20$ years & 2 & 0.91 & 9 & 4.11 \\
\hline $20-29$ years & 112 & 50.68 & 35 & 15.98 \\
\hline $30-39$ years & 98 & 44.75 & 125 & 56.62 \\
\hline $40-49$ years & 8 & 3.65 & 47 & 21.46 \\
\hline Older than 50 years & 0 & 0.00 & 4 & 1.83 \\
\hline \multicolumn{5}{|l|}{ Education } \\
\hline Postgraduate degree & 33 & 15.00 & 35 & 15.98 \\
\hline Bachelor's degree & 150 & 68.18 & 114 & 51.60 \\
\hline Some education after high school & 12 & 5.45 & 33 & 15.07 \\
\hline High school certificate (12 years of education) & 23 & 10.45 & 27 & 12.33 \\
\hline Intermediate school certificate ( 9 years of education) & 1 & 0.45 & 4 & 0.00 \\
\hline Primary school certificate ( 6 years of education) & 0 & 0.00 & 5 & 2.28 \\
\hline No schooling completed & 1 & 0.45 & 2 & 0.91 \\
\hline \multicolumn{5}{|l|}{ Occupation } \\
\hline Employed, full time & 66 & 30.00 & 183 & 83.18 \\
\hline Employed, part time & 12 & 5.45 & 16 & 7.27 \\
\hline Self-employed & 1 & 0.45 & 11 & 5.00 \\
\hline Not employed & 121 & 55.00 & 3 & 1.36 \\
\hline Student & 20 & 9.09 & 2 & 0.91 \\
\hline Retired & 0 & 0.00 & 3 & 1.36 \\
\hline Disabled, not able to work & 0 & 0.00 & 2 & 0.91 \\
\hline \multicolumn{5}{|l|}{ Language spoken with child } \\
\hline Arabic & 146 & 66.37 & 193 & 87.73 \\
\hline English & 1 & 0.45 & 1 & 0.45 \\
\hline Mixture of Arabic and English & 73 & 33.18 & 26 & 11.82 \\
\hline
\end{tabular}


Table 2

Socioeconomic Characteristics of the Households/Children

\begin{tabular}{|c|c|c|}
\hline Household characteristics & $n$ & $\%$ \\
\hline \multicolumn{3}{|l|}{ Place of residence } \\
\hline Riyadh, Saudi Arabia & 95 & 43.18 \\
\hline Jeddah, Saudi Arabia & 42 & 19.09 \\
\hline Other, Saudi Arabia & 83 & 37.73 \\
\hline \multicolumn{3}{|l|}{ Type of tenure } \\
\hline Rented & 111 & 50.68 \\
\hline Owned & 98 & 44.75 \\
\hline Provided by employer & 4 & 1.83 \\
\hline Other & 6 & 2.74 \\
\hline \multicolumn{3}{|l|}{ Monthly household income ${ }^{a}$} \\
\hline Lower-income & 70 & 32.11 \\
\hline Middle-income & 89 & 40.83 \\
\hline Higher-income & 59 & 27.06 \\
\hline \multicolumn{3}{|c|}{ Availability of domestic helper/ nanny } \\
\hline Yes & 73 & 33.18 \\
\hline No & 147 & 66.82 \\
\hline Child characteristics & $n$ & $\%$ \\
\hline \multicolumn{3}{|l|}{ Child's age } \\
\hline $12-23$ months & 86 & 39.09 \\
\hline 24-36 months & 134 & 60.91 \\
\hline \multicolumn{3}{|l|}{ Child's gender } \\
\hline Female & 107 & 48.64 \\
\hline Male & 113 & 51.36 \\
\hline \multicolumn{3}{|l|}{ Child's birth order } \\
\hline Oldest & 46 & 20.91 \\
\hline Middle & 13 & 5.91 \\
\hline Youngest & 104 & 47.27 \\
\hline Only & 57 & 25.91 \\
\hline \multicolumn{3}{|c|}{ Relationship of respondent to child } \\
\hline Mother & 217 & 98.64 \\
\hline Father & 1 & 0.46 \\
\hline Sister & 1 & 0.46 \\
\hline Aunt & 1 & 0.46 \\
\hline \multicolumn{3}{|c|}{${ }^{a}$ For the purpose of this study, lower-income was defined as families earning less than SAR } \\
\hline \multicolumn{3}{|c|}{$\begin{array}{l}10,000 \text { a month; middle-income was families earning between SAR 10,000 and SAR 19,999 a } \\
\text { month, and higher-income was families earning over SAR 20,000 a month (SAR } 1=\text { USD } 0.267 \\
\text { as of June 1, 2016; SAR = Saudi Arabian Riyal). According to the Saudi General Authority for } \\
\text { Statistics, the median monthly household income in } 2013 \text { was SAR 10,723 (The Saudi General } \\
\text { Authority for Statistics, 2013). }\end{array}$} \\
\hline
\end{tabular}




\section{Procedures}

Participation in the study was voluntary. Ethical approval for the study was received from the University of Manchester's Ethics Review Board. Potential participants were invited to complete an anonymous online survey. The survey was constructed using the online data collection engine Survey Monkey and was administered in Arabic. Information on the purpose of the study was provided and informed consent was obtained from all participants.

\section{Survey}

This study's findings are based on caregivers' responses to a 72-item questionnaire (see Appendix A) about their children's environment and screen media use. In order to ensure content validity when developing the survey, previous research was reviewed and instruments designed to assess similar topics were consulted (e.g., Rideout, 2013; Wartella, Rideout, Lauricella, \& Connell, 2014). Then, a list of survey items that aimed to measure the constructs of interest was generated. Items were presented in various formats including yes/no questions, checklists, open-ended questions, and Likert scales.

Nine of the target child's screen media use items (i.e., Items No. 33, 37, 40, 41, 42, 43, 44, 51, and 52) were adapted from the Common Sense Media Zero to Eight Survey (Rideout, 2013), an instrument that has been used in previous research to assess children's screen media use (e.g., Bedford, Saez de Urabain, Celeste, Karmiloff-Smith, \& Smith, 2016; Kabali et al., 2015; Lauricella, Wartella, \& Rideout, 2015; Wartella et al., 2013). Four of the questions regarding parents' attitudes towards children's media use and parental media mediation practices (i.e., Items No. 38, 53, 55, and 58) were adapted from the Common Sense Media Zero to Eight Survey (Rideout, 2013) and the Parenting in the Age of Digital Technology Survey (Wartella et al., 2014). The remainder of the current study's survey items were developed by the the first author. 


\section{Analysis}

Statistical analysis was performed using the R statistical package (version 3.4.2).

Data were evaluated using descriptive statistics to assess measures of central tendency and variation. When investigating the amount of time children were exposed to screen media, we divided the children into two age groups: a younger group aged 1 to 2 years $(n=86, M=$ 18.12 months, $S D=3.40$ months) and an older group aged 2 to 3 years $(n=134, M=29.98$ months, $S D=3.43$ months). A Student's t-test for independent samples was used to determine the significance of differences between these two age groups with regard to amount of screen time. The significance level used was $\alpha=.05$.

\section{Results}

The results are organised according to the research questions that were presented earlier.

\section{How Prevalent Is Access to Screen Media in Saudi Toddlers' Homes?}

Table 3 shows the availability of screen media in the households of Saudi toddlers in this sample.

Table 3

Prevalence of Screen Media in Saudi Households with Toddlers

\begin{tabular}{lcc}
\hline & $\boldsymbol{n}$ & $\mathbf{\%}$ \\
\hline Screen media devices at home (Survey item No. 35) & & \\
Households that had at least one television set & 213 & 96.82 \\
Households that had at least one smartphone & 210 & 95.45 \\
Households that had at least one desktop computer or laptop & 203 & 92.27 \\
Households that had at least one tablet & 169 & 76.82 \\
Households that had at least one game console (e.g., PlayStation, Xbox, or & 85 & 38.64 \\
Wii) & & \\
Households that had at least one DVD player or VCR & 72 & 32.73 \\
Households that had at least one iPod Touch or other type of video iPod & 46 & 20.91 \\
Households that had at least one handheld video game player (e.g., & 15 & 6.82 \\
Gameboy or PSP) & & \\
Screen media devices in child's bedroom (Survey item No. 37) & & \\
Toddlers with a screen media device in their bedroom & 28 & 12.73 \\
Toddlers with a television in their bedroom & 25 & 11.36 \\
Toddlers with a game console in their bedroom & 6 & 2.73 \\
Toddlers with a PC or laptop in their bedroom & 5 & 2.27
\end{tabular}


Toddlers with a DVD player in their bedroom

Children who had their own mobile media device (Survey item No. 44)

Tablet

Smartphone

Tablet ownership among the younger group

Tablet ownership among the older group

Smartphone ownership among the younger group

Smartphone ownership among the older group

Children who shared a mobile media device with another family member (Survey item No. 45)

\section{Internet connection}

Households that had an Internet connection (Survey item No. 36)

Toddlers who 'always' or 'often' had Internet connection available for the

\section{Background TV \& media at mealtime}

Households that had TV 'always' or 'often' on even if no one is actually watching it (Survey item No. 55 [sub-item No. 10])

Toddlers who 'always' or 'often' ate their meals while consuming media (Survey item No. 55 [sub-item No. 9])

\footnotetext{
${ }^{a}$ Among children aged 1 to 3 years in the sample who owned their own media device.

${ }^{\mathrm{b}}$ Among all children in the younger group.

${ }^{\mathrm{c}}$ Among all children in the older group.
}

\section{How Early in Life Do Saudi Children Start to View/Use Screen Media?}

To calculate the mean age of starting to view screens (Survey items No. 63 and 64), children who had never been exposed to television $(n=8 ; 4 \%)$ or mobile media $(n=22$; $10 \%$ ) were excluded. All children who had already started viewing screens began viewing at the age of 2 years or younger. Among children who watched television, the median age of starting to watch television was 12 months $(M=14.19$ months; $S D=6.92$; Figure 1$)$. Among those who used mobile media, the median age of starting to consume mobile media was 18 months $(M=18.77$ months; $S D=7.58$; Figure 2$)$. 


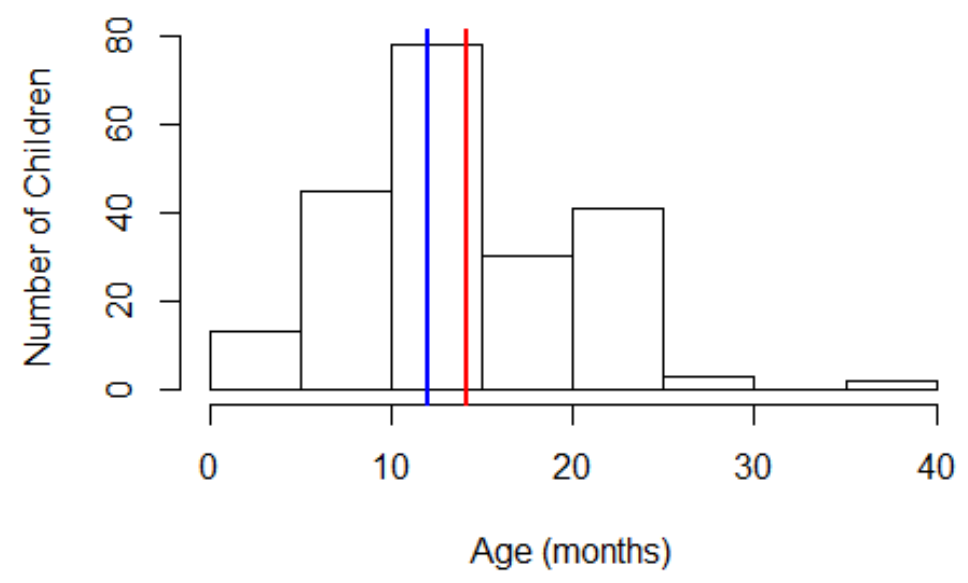

Figure 1. Onset age of television viewing. The red line represents the mean. The blue line represents the median.

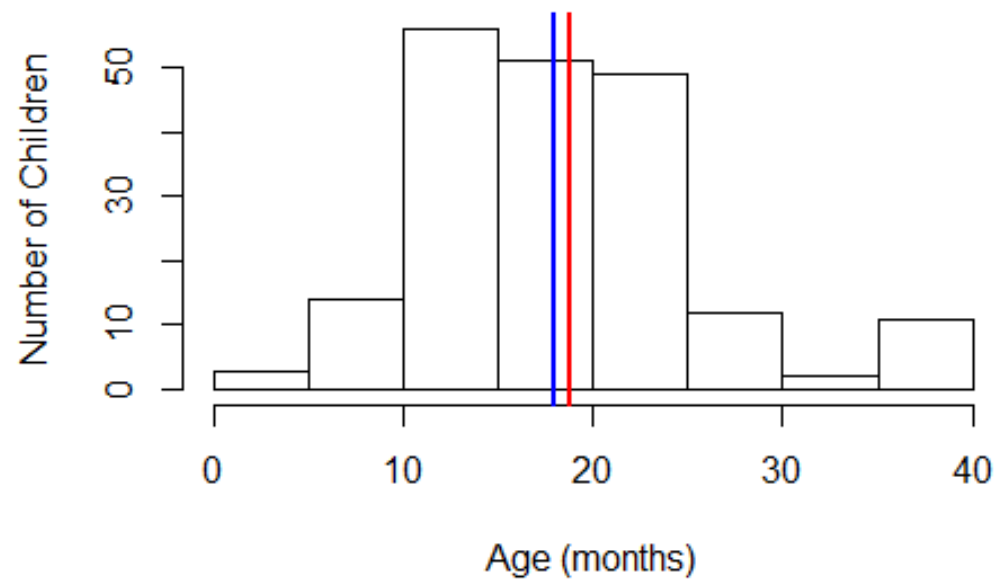

Figure 2. Onset age of mobile media use. The red line represents the mean. The blue line represents the median.

\section{How Much Time Do Saudi Toddlers Spend Consuming Screen Media?}

The current study looked at the amount of time that young Saudi children spent viewing television (Survey item No. 46) and the amount of time that they spent using mobile media (Survey item No. 48), and then measured their overall screen time against the AAP recommendations.

Overall screen time. Overall screen time (as reported by the caregivers) was calculated for all children in the sample including those who never used screens. Figure 3 shows that the mean overall screen time for 1- to 3-year-old children was about 3 hours per 
day $(M=194.1$ minutes, $S D=154.70$ minutes $)$. Overall screen time was higher for the older group $(M=206.01$ minutes, $S D=150.48$ minutes $)$ than the younger group $(M=175.35$ minutes, $S D=160.25$ minutes). However, a Student's t-test for independent samples showed that this difference was not statistically significant, $t(217)=-1.43, p=.154$.

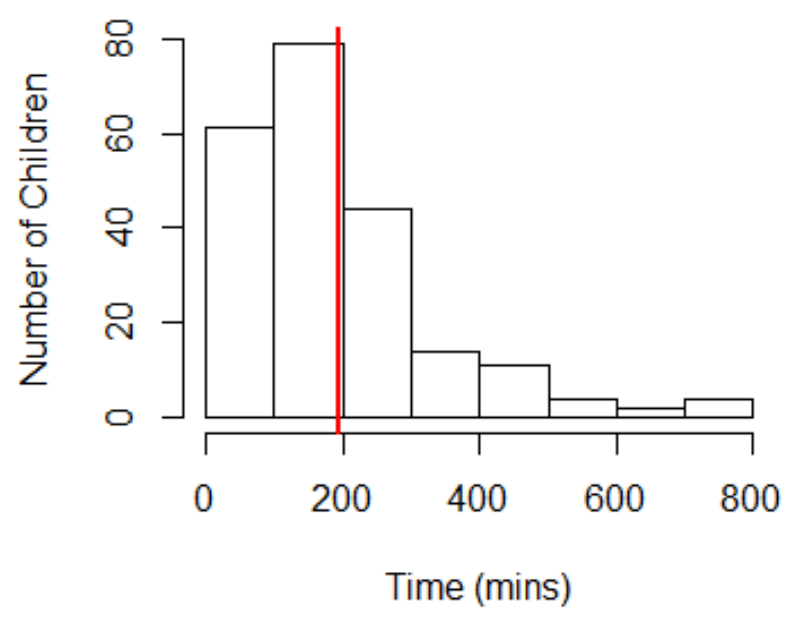

Figure 3. Overall screen time in minutes. Including non-users. The red line represents the mean.

Amount of television viewing. Respondents were asked to report the number of hours or minutes per day their children spend watching television. The mean television time for 1- to 3-year-old children was about 2 hours per day $(M=125.30$ minutes, $S D=111.24$ minutes; Figure 4). No significant difference was observed as a function of age group (younger group: $M=125.12$ minutes, $S D=113.69$ minutes; older group: $M=125.37$ minutes, $S D=110.10$ minutes; $t(217)=-0.02, p=.987)$. 


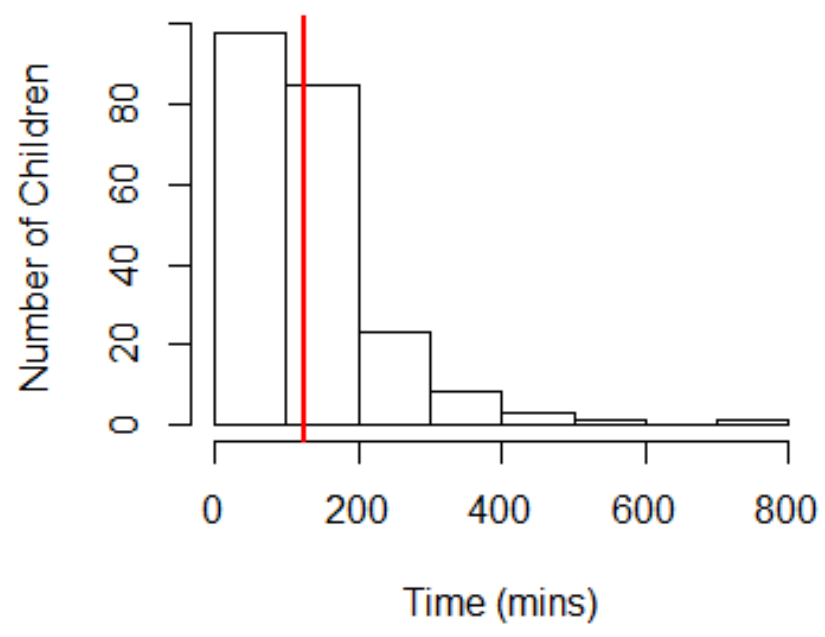

Figure 4. Amount of television viewing time in minutes. Includes non-users. The red line represents the mean.

Amount of mobile media use. Respondents were asked to report the number of hours or minutes per day their children spend using or viewing mobile media. The mean mobile media time for 1- to 3-year-old children was about 1 hour per day $(M=69.07$ minutes, $S D=83.28$ minutes; Figure 5). A significant difference was observed as a function of age group (younger group: $M=51.05$ minutes, $S D=75.83$ minutes; older group: $M=$ 80.63 minutes, $S D=86.02$ minutes; $t(218)=-2.61, p=.010$; see Figure 6).

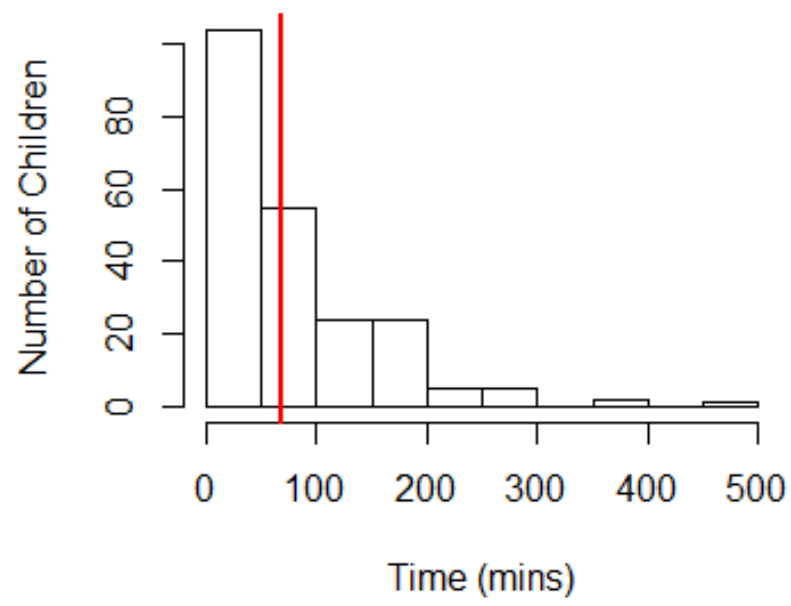

Figure 5. Amount of mobile media time in minutes. Includes non-users. The red line represents the mean. 


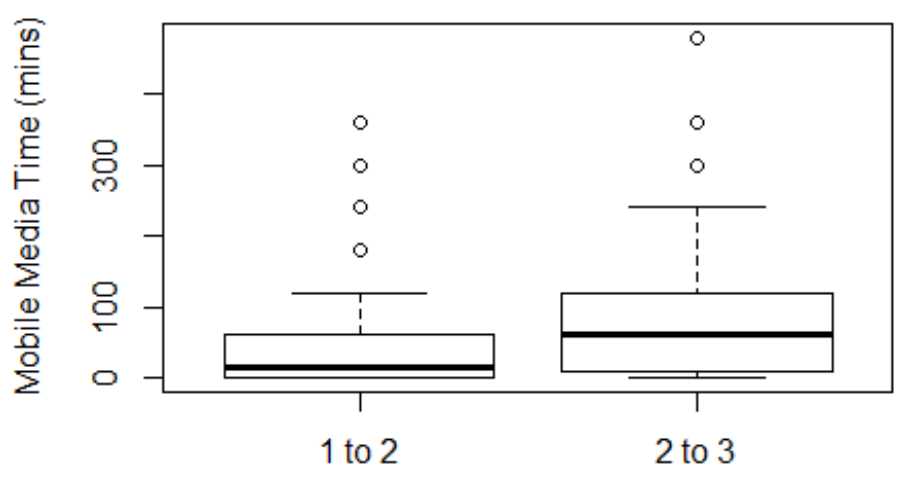

Age Groups

Figure 6. Time spent using mobile media devices across age groups. Includes non-users. The bold horizontal lines represent median values.

The majority (91\%) of children in the younger group exceeded the AAP recommendation for screen time for children under 2 years. On average, the 1- to 2-year-olds in this study viewed screens for about 3 hours $(M=175.35$ minutes, $S D=160.25$ minutes) more, daily, than the AAP recommendation of zero screen time. The majority (82\%) of the children in the older group viewed screens for more than 1 hour a day and thus exceeded the AAP screen time recommendation for their age. On average, the 2- to 3-year-olds viewed screens for about 2 and a half hours more than the AAP recommendation of a maximum of 1 hour of screen time per day ( $M=206.01$ minutes, $S D=150.48$ minutes $)$.

\section{How Prevalent are Screen Media, Compared to Reading, Among Saudi Toddlers?}

When asked about the number of children's print books available to the target children at home, including books shared with siblings (Survey item No. 31), caregivers' responses indicated that more than a quarter $(26 \%)$ of Saudi households with toddlers had absolutely no books for children, and about a quarter (27\%) had only one or two books (Figure 7). 


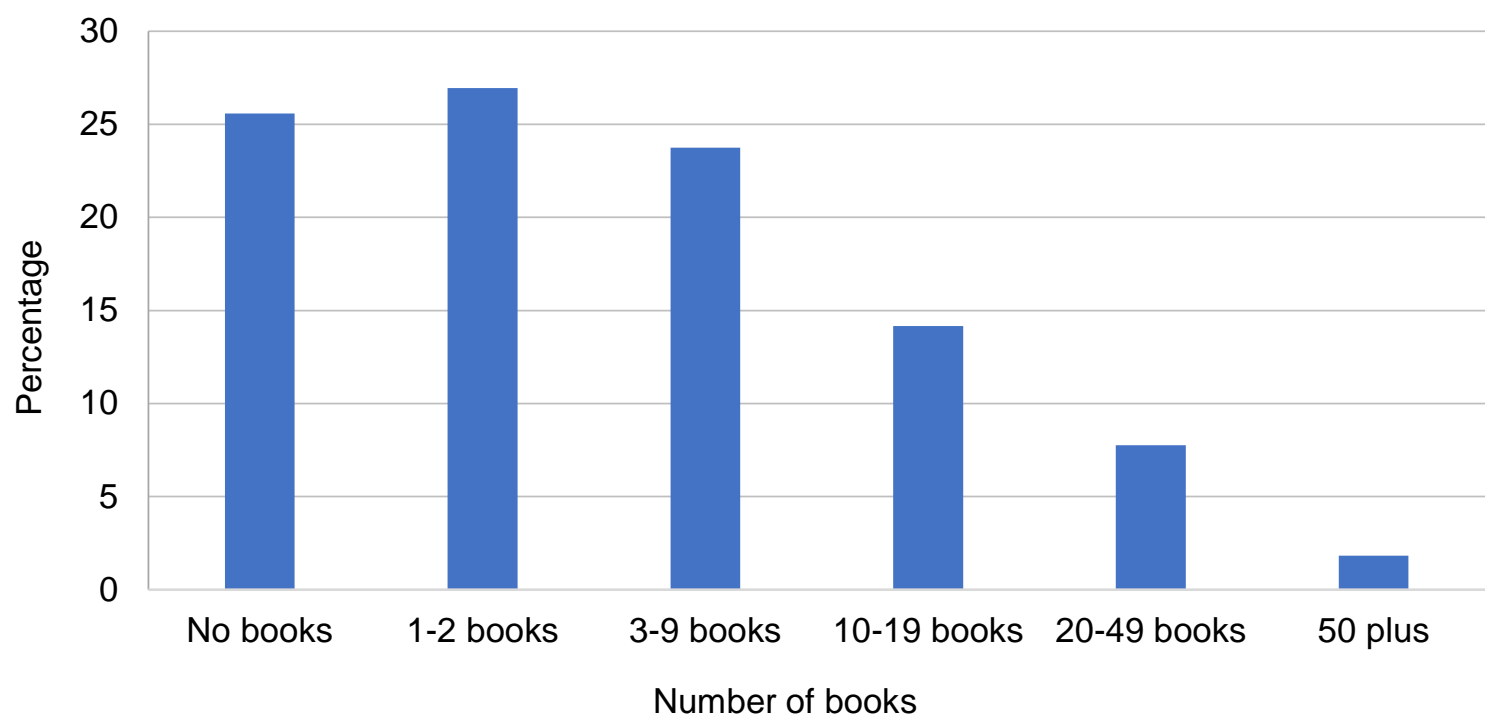

Figure 7. Number of children's books at home.

Figure 8 shows a comparison between the frequencies of reading, television viewing, and mobile media use in our sample (Survey item No. 52 [sub-items No. 1, 3, and 7]). Watching television was the most prevalent activity that young children engaged in daily (68\%), followed by using mobile media devices such as tablets and smartphones (35\%). Viewing screens in general was much more prevalent in children's lives than reading; only $17 \%$ of children were read to daily. Notably, about $41 \%$ of mothers 'never' read to their children, whereas TV was watched 'several times a day' by about $42 \%$ of the children. 


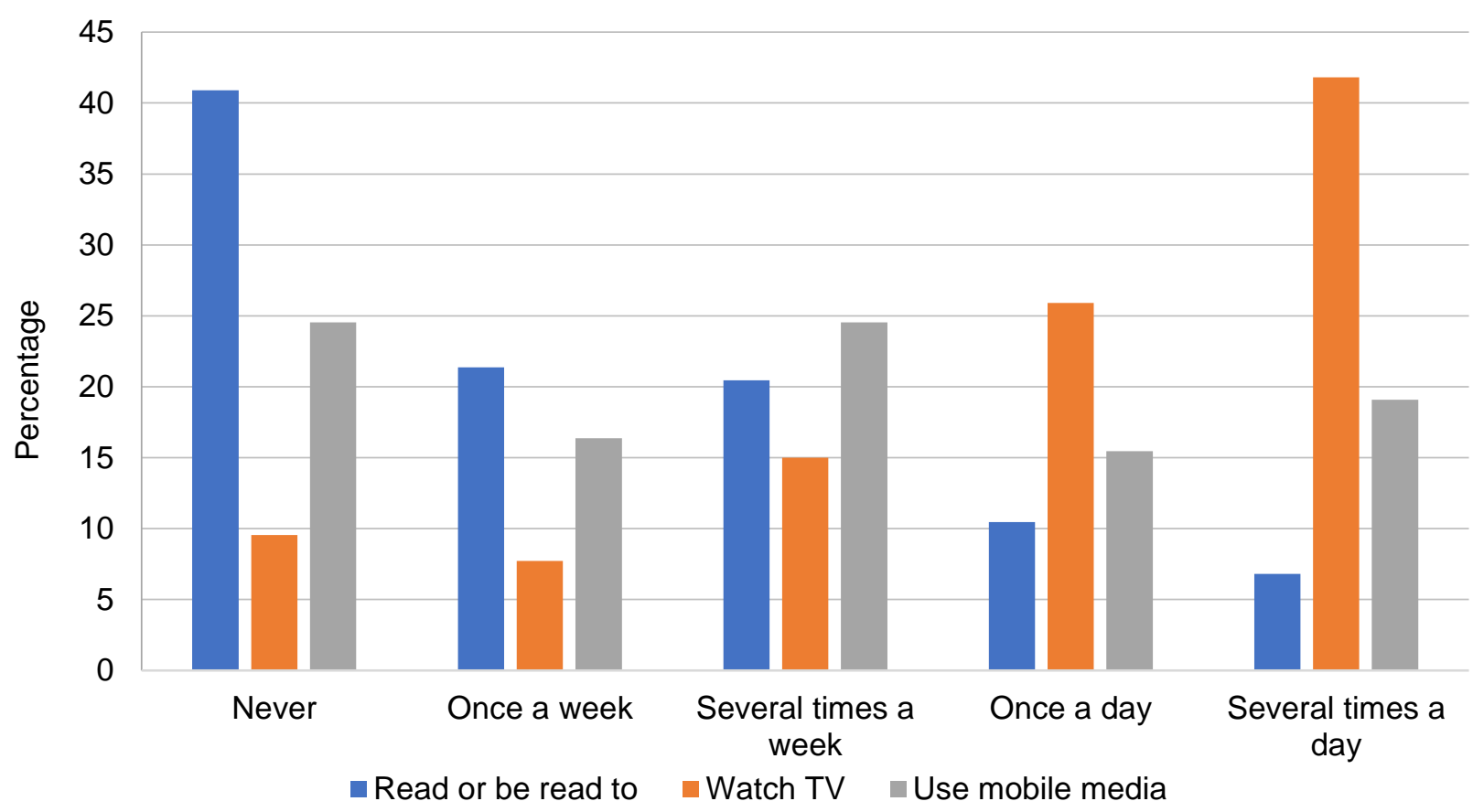

Figure 8. Frequency of reading, TV viewing, and mobile media use.

\section{What Are Saudi Toddlers' Most Viewed Mobile Media Content Types?}

Mothers reported how often their children used specific types of apps on a cell phone, iPad, or other tablet device. (see Table 4). The most popular type of mobile media content was "apps and programmes that have video songs", as about $43 \%$ of the caregivers reported that their children "always" or "often" use them. On the other hand, "creative apps and programmes for things like drawing, making music, or creating videos" was found to be the least popular type of mobile media content among toddlers, with about $18 \%$ of the caregivers reporting that their children "always" or "often" use them. 
Table 4

Percentages of the Frequency of Children's Viewing/Using of Different Types of Screen Media Programmes and Apps

\begin{tabular}{lccccc}
\hline Type of programmes or apps & Never & Rarely & Sometimes & Often & Always \\
\hline 1. Apps that have video songs & 16.84 & 11.05 & 26.32 & 19.47 & 23.68 \\
2. Apps that have photo and video albums & 22.75 & 11.64 & 26.46 & 16.93 & 21.16 \\
3. Educational games like puzzles, memory & 30.32 & 9.57 & 20.74 & 21.28 & 16.49 \\
games, maths, or reading & 30.32 & 13.30 & 20.74 & 17.02 & 15.43 \\
4. Apps that have audio songs & 28.88 & 13.37 & 23.53 & 18.72 & 14.44 \\
5. Games that are just for fun & 43.39 & 10.05 & 16.93 & 12.70 & 13.76 \\
$\begin{array}{l}\text { 6. Apps based on a character child knows from a } \\
\text { TV show }\end{array}$ & 26.98 & 21.16 & 27.51 & 9.52 & 13.23 \\
7. Apps with religious content like teaching the & & & & & \\
Quran, prayers, and Islamic rituals & 46.84 & 18.95 & 13.68 & 10.53 & 7.89 \\
$\begin{array}{l}\text { 8. Creative apps for things like drawing, making } \\
\text { music, or creating videos }\end{array}$ & 52.69 & 17.74 & 13.44 & 3.23 & 4.30 \\
9. Other types of programmes and apps & & & & & \\
\hline
\end{tabular}

How Do Screen Media Practices among Saudi Children Compare to Those Reported in the U.S. and the UK?

In order to place the current data in an international context, some of the main findings from this study were compared against those reported for children in the United States (Rideout, 2017) and the United Kingdom (Bedford et al., 2016; CHILDWISE, 2017; Kucirkova \& Littleton, 2016). These comparisons, however, should be treated with caution as there are variations in methodologies and children's age ranges across the studies (Table 5 and Table 6). 
Table 5

Comparison Between Media Use Patterns Among Children in Saudi Arabia, the U.S., and the UK

\begin{tabular}{|c|c|c|c|c|c|c|c|c|c|}
\hline & $\begin{array}{c}\text { Saudi } \\
(1-2 Y)^{a}\end{array}$ & $\begin{array}{l}\text { Saudi } \\
(2-3 Y)^{a}\end{array}$ & $\begin{array}{c}\text { Saudi } \\
(1-3 Y)^{a}\end{array}$ & $\begin{array}{c}\text { U.S. } \\
(0-2 Y)^{a}\end{array}$ & $\begin{array}{c}\text { U.S. } \\
(2-4 Y)^{\mathrm{a}}\end{array}$ & $\begin{array}{c}\text { UK } \\
(6-36 \mathrm{mos})^{b}\end{array}$ & $\begin{array}{c}\text { UK } \\
(0-2 Y)^{\mathbf{c}}\end{array}$ & $\begin{array}{c}\text { UK } \\
(0-4 Y)^{c}\end{array}$ & $\begin{array}{c}\text { UK } \\
(0-8 Y)^{d}\end{array}$ \\
\hline Average TV time per day ${ }^{\mathrm{e}}$ & $02: 05$ & 02:05 & $02: 05$ & $00: 29$ & 01:09 & - & - & - & - \\
\hline Average MM time per day ${ }^{\mathrm{e}}$ & $00: 51$ & 01:20 & 01:09 & 00:07 & $00: 58$ & $00: 24^{\mathrm{f}}$ & - & - & - \\
\hline Average overall screen time per day ${ }^{\mathrm{e}}$ & $02: 55$ & $03: 26$ & $03: 14$ & $00: 42$ & $2: 39$ & - & $2: 24^{g}$ & $2: 36^{\mathrm{g}}$ & - \\
\hline$\%$ of children who own a tablet & $17 \%$ & $25 \%$ & $22 \%$ & $5 \%$ & $43 \%$ & $10 \%^{\mathrm{a}, \mathrm{h}}$ & - & $33 \%{ }^{\mathrm{g}}$ & - \\
\hline$\%$ of children who own a smartphone & $1 \%$ & $3 \%$ & $2 \%$ & $1 \%$ & $3 \%$ & - & - & - & - \\
\hline$\%$ of children who are read to daily & $12 \%$ & $21 \%$ & $17 \%$ & $43 \%$ & $56 \%$ & - & - & - & $56 \%$ \\
\hline
\end{tabular}

Note. Data on children in the U.S. were adapted from Rideout (2017); Y = years; mos = months; MM = mobile media

${ }^{a}$ Among all children: users and non-users of media

${ }^{\mathrm{b}}$ Based on data adapted from Bedford, Saez de Urabain, Celeste, Karmiloff-Smith, and Smith (2016)

${ }^{c}$ Based on data adapted from CHILDWISE (2017)

${ }^{\mathrm{d}}$ Based on data adapted from Kucirkova and Littleton (2016)

${ }^{\mathrm{e}}$ In hours and minutes (hh:mm)

${ }^{\mathrm{f}}$ Among those who ever used media

${ }^{\mathrm{g}}$ Not clear from the report whether this value was calculated for all children or for media users only

${ }^{\text {h }}$ Percentage of children who own a touchscreen device 
Table 6

Comparison Between the Onset Age of Screen Media Use Among Children in Saudi Arabia, the U.S., and the UK

\begin{tabular}{lccc}
\hline & Saudi (1-3Y) & U.S. (0-2Y) & UK (6-36 mos) \\
\hline$\%$ of children who started watching TV before age 2 & $94 \%$ & $71 \%$ & - \\
$\%$ of children who started using MM before age 2 & $79 \%$ & $46 \%$ & $81 \%$
\end{tabular}

Note. Data on children in the U.S. were adapted from Rideout (2017); Y = years; mos = months; MM = mobile media

${ }^{a}$ Among all children: users and non-users of media

${ }^{\mathrm{b}}$ Based on data adapted from Bedford, Saez de Urabain, Celeste, Karmiloff-Smith, and Smith (2016) 


\section{Discussion}

The purpose of this study was to provide a better understanding of screen media use among young children in Saudi Arabia, the largest media market in the MENA region. More specifically, the study sought to provide information on the prevalence of screen media devices in Saudi households with toddlers, the age at which young children are introduced to screens, the amount of time they spend with screens, the prevalence of reading among toddlers compared to media use, the types of mobile media content children frequently view, and how screen media use practices in Saudi Arabia compare to those in other countries.

Saudi homes with toddlers are saturated with media devices and new technology. The vast majority in this study reported ownership of TVs, computers, smartphones, tablets, and an Internet connection. Handheld video game players, however, were not prevalent among households with toddlers. This could be due to the sophistication of video game players and the motor and cognitive skills needed to use them, which young children have not mastered yet. One quarter of children under 3 in this study had their own portable media devices. In line with previous results (e.g., Bedford et al., 2016; Cheung, Bedford, Saez De Urabain, Karmiloff-Smith, \& Smith, 2017; Rideout, 2011), the current study showed that ownership of portable devices among young children increases with age.

The current study also shows that more than $90 \%$ of children in the sample started watching television and using mobile media devices before the age of 2 . This figure is considerably higher than that reported by the Saudi National Center for Public Opinion Polls (2017a), which found that less than half of Saudi children in their sample aged 5 to 12 years started using smart media devices before the age of 5 years. This discrepancy could be attributed to the different target age groups and the different media platforms examined.

In the current study, Saudi children exceeded the maximum amount of screen time recommended by several international health bodies. The average overall screen time for 
Saudi toddlers was found to be about 3 hours a day, which exceeds the AAP recommendations for children aged 2 to 5 years. It is worth noting that we looked at screen time among all children in the sample, including those who were never exposed to screens, which may have affected the mean screen time calculated. Although our findings are higher than the AAP recommendations, they are still low compared to results of the Saudi National Center for Public Opinion Polls (2017a), which reported that Saudi children aged 5 to 12 years in their sample spent 4 hours per day using mobile media devices. These discrepancies may be the result of the broader age range examined by the Saudi National Center for Public Opinion Polls.

We found no significant differences by age group with regard to the amount of time children spent viewing television. However, just as older children were more likely to own a mobile media device than younger children (under 2 years of age), in accordance with other studies (e.g., Li, Mendoza, \& Milanaik, 2017), they also spent significantly more time using mobile media than younger children. This may be because television viewing can be a shared experience for the whole family and does not require any sophisticated skills, unlike mobile media, which provide a more individual experience that requires higher and more complex cognitive and motor skills.

Put in a global context, ownership of tablets among children aged 2 to 4 years in the U.S. (Rideout, 2017) is almost twice the figure for Saudi children aged 2 to 3 years (as found in the current study). Interestingly, however, ownership of tablets among Saudi children under 2 is about three times as high as that among children under 2 in the U.S. Saudi children start viewing screens earlier than young children in the U.S. (Rideout, 2017), but at almost the same time as children in the UK (Bedford et al., 2016). In addition, the average amount of time Saudi toddlers are exposed to screen media is higher than in the U.S. (Rideout, 2017) and the UK (Bedford et al., 2016). These findings make sense in light of the 
observation that the AAP has been successful reaching out to parents in the U.S. through media outlets and paediatricians (Rideout, 2017). The AAP specifically discourages the use of screen media by children under 2 years, and this could explain why parents in the U.S. seem to be more diligent in complying with the AAP guidelines up to the age of 2 . No similar guidelines or awareness raising efforts are in place in Saudi Arabia. Similarly, in the UK, there are still no official guidelines on screen time, although the topic of issuing guidelines is highly debated (Etchells et al., 2017; Palmer et al., 2016; UK Parliament, 2018). This may explain the earlier exposure to screen media among UK children under the age of 2. The present study revealed notable findings on the prevalence of reading to young children in Saudi Arabia. More specifically, we found that reading to toddlers is very infrequent in Saudi Arabian homes, with reports of more than $40 \%$ of children never being read to, one quarter of children having no children's books at home, and more than half having no more than two children's books at home. A substantial body of research indicates that shared reading is one of the most prominent home literacy environment components that are positively associated with concurrent and long-term language and literacy outcomes (e.g., Farrant \& Zubrick, 2011; Evans et al., 2000; Ninio, 1983; Payne et al., 1994; Whitehurst \& Lonigan, 1998). The figures found in the current study are worrying, especially when compared to global figures. For example, previous research in the UK has indicated that more than half of children aged 0 to 8 years are read to daily (Kucirkova \& Littleton, 2016), and studies in the U.S. have shown that more than half of children aged 2 to 4 years and more than two fifths of children under 2 years old are read to daily (Rideout, 2017).

It is not entirely clear why the daily reading rates among Saudi parents and children are low. It is possible that the culture of reading for pleasure is not very common among Saudis in general (Saudi National Center for Public Opinion Polls, 2017b). It could also be that parents thought that their children were too young for reading and may not understand 
what is read to them. Another possibility is that screen time displaces time spent on reading. This possibility is supported by previous research suggesting that screen media use may displace other enriching activities such as reading, parent-child interactions, and play (e.g., Anderson \& Pempek, 2005; Huston, Wright, Marquis, \& Green, 1999; Vandewater, Bickham, \& Lee, 2006).

It is important not only to find out how much children watch, but also what they watch, as media content has been shown to have an effect on the extent to which children learn from media (Anderson, Huston, Schmitt, Linebarger, \& Wright, 2001; Rice, Huston, Truglio, \& Wright, 1990; Tomopoulos et al., 2010). The study revealed that the most viewed content genre on mobile media devices was children's songs. Educational apps and games were used less often than apps with video clips and video songs. This is in contrast to the findings of Rideout (2013) and Li et al. (2017), who found that toddlers and pre-schoolers in the U.S. engage with educational games and apps more than with other types of apps. Confirming the findings of the Saudi National Center for Public Opinion Polls (2017a), creative apps for activities such as drawing, making music, or creating videos were the least popular among children in our sample. This could be attributed to the sophistication of these types of apps and the higher cognitive and motor skills that they require.

There are limitations to this study. First, parent-reported measures are susceptible to social desirability and recall bias. However, as the target age group in this study was children under 3 years, obtaining data directly from the children was not an option. In order to reduce the potential for social desirability effects, when constructing the survey, we phrased questions carefully so respondents could provide answers about their children's media practices without fear of being judged. We did not mention, nor hint at, any negative or positive aspects associated with screen media use by young children. 
Second, tools other than questionnaires may be more accurate in reporting children's media use practices. Time-use and event-based diaries, for example, have been found to be less subject to social desirability bias and memory lapses than checklists and questionnaires (Anderson, Field, Collins, Lorch, \& Nathan, 1985; Ellis-Davies, Sakkalou, Fowler, Hilbrink \& Gattis, 2012). Diaries can be difficult to complete, though, which may negatively affect the response rate and the sample size. Another alternative is the use of electronic monitoring techniques such as apps that can be downloaded on children's devices to track their mobile media use and media content viewed. However, due to technical and ethical restrictions, these methods were not viable for this study. Surveys were thus more useful and practical for obtaining information about children's screen media use patterns from their primary caregivers.

Finally, the majority of the mothers in the study were well-educated and therefore our findings might not accurately generalise to the larger population. Regardless, future work should examine whether the same media profiles can be found in children of mothers from a more widely distributed educational attainment spectrum.

\section{Conclusions}

The current study sought to provide a better understanding of the home screen media environment of Saudi toddlers. We found that the majority of Saudi toddlers start viewing screens prior to the age recommended by several child health organisations. We also found that Saudi toddlers' screen time exceeds the maximum amount of recommended screen time for their age. Furthermore, we found that many Saudi households do not regularly engage in reading to their toddlers.

The first three years of life are very critical, and exposure to screen media during these years is likely to play a significant role in children's development. However, research on exposure to screen media among Saudi children under 3 years of age is scarce. We 
recommend that future studies be conducted in the MENA region in general, and in Saudi Arabia in particular, to guide the development of recommendations for all stakeholders on the use of screen media by young children. 


\section{References}

Al-Agha, A. E., Nizar, F. S., \& Nahhas, A. M. (2016). The association between body mass index and duration spent on electronic devices in children and adolescents in Western Saudi Arabia. Saudi Medical Journal, 37(4), 436-439.

doi:10.15537/smj.2016.4.15018

American Academy of Pediatrics. (2011). Media use by children younger than 2 years. Pediatrics, 128(5), 1040-1045.

American Academy of Pediatrics. (2013). Children, adolescents, and the media. Pediatrics, 132(5), 959-960.

American Academy of Pediatrics. (2016). Media and young minds. Pediatrics, 138(5). doi:10.1542/peds.2016-2591.

Anderson, D. R., \& Pempek, T. A. (2005). Television and very young children. American Behavioral Scientist, 48(5), 505-522

Anderson, D. R., \& Subrahmanyam, K. (2017). Digital screen media and cognitive development. Pediatrics, 140(2), S57-S61. doi:10.1542/peds.2016-1758C

Anderson, D. R., Huston, A. C., Schmitt, K. L., Linebarger, D. L., \& Wright, J. C. (2001). Early childhood television viewing and adolescent behavior: The Recontact Study. Monographs of the Society for Research in Child Development, 66(1), 1-143. doi:10.2307/3181552

Anderson, D. R., Field, D. E., Collins, P. A., Lorch, E. P. \& Nathan, J. G. (1985). Estimates of young children's time with television: A methodological comparison of parent reports with time-lapse video home observation. Child Development, 56, 1345-1357.

Australian Department of Health. (2017). Australian 24-hour movement guidelines for the early Years (birth to 5 years): An integration of physical activity, sedentary behaviour, and sleep. Retrieved from 
http://www.health.gov.au/internet/main/publishing.nsf/content/F01F92328EDADA5B CA257BF0001E720D/\$File/Birthto5years_24hrGuidelines_Brochure.pdf

Bedford, R., Saez de Urabain, I. R., Celeste, C. H., Karmiloff-Smith, A., \& Smith, T. J. (2016). Toddlers' fine motor milestone achievement is associated with early touchscreen scrolling. Frontiers in Psychology, 7, 1-8. doi:10.3389/fpsyg.2016.01108 Bornstein, M. H. (2015). Infancy and human development. In J. D. Wright (Ed.), International Encyclopaedia of Social \& Behavioral Sciences $\left(2^{\text {nd }}\right.$ ed, Vol. 12, pp. 713). Oxford: Elsevier Ltd. doi:10.1016/B978-0-08-097086-8.23138-3

Bradley, R. H., Caldwell, B. M., Rock, S. L., Ramey, C. T., Barnard, K. E., Gray, C., . . Johnson, D. L. (1989). Home environment and cognitive development in the first three years of life: A collaborative study involving six sites and three ethnic groups in North America. Developmental Psychology, 25, 217-235.

Canadian Paediatric Society. (2017). Screen time and young children: Promoting health and development in a digital world. Paediatrics \& Child Health, 461-468. doi:10.1093/pch/pxx123. Retrieved from https://academic.oup.com/pch/articlepdf/22/8/461/22030838/pxx123.pdf

Cheung, C. H. M., Bedford, R., Saez De Urabain, I. R., Karmiloff-Smith, A., \& Smith, T. J. (2017). Daily touchscreen use in infants and toddlers is associated with reduced sleep and delayed sleep onset, Scientific Reports, 7, 46104. doi:10.1038/srep46104

CHILDWISE. (2017). The monitor pre-school report 2017: Key behavior patterns among 04 year olds. Retrieved from http://www.childwise.co.uk/preschool.html Chonchaiya, W., \& Pruksananonda, C. (2008). Television viewing associates with delayed language development. Acta Paediatrica, 97, 977-982. 
Christakis, D. A. (2014). Interactive media use at younger than the age of 2 years: Time to rethink the American Academy of Pediatrics guideline? JAMA Pediatrics, 168(5), 399-400. doi:10.1001/jamapediatrics.2013.5081

Dubai Press Club \& Dubai Media City. (2016). Arab Media Outlook 2016-2018: Youth, content, digital media. Dubai, United Arab Emirates. Retrieved from http://dubaistudiocity.ae/uploads/AMO-Eng.pdf

Ellis-Davies, K., Sakkalou, E., Fowler, N. C., Hilbrink, E. E., \& Gattis, M. (2012). CUE: The continuous unified electronic diary method. Behavior Research Methods, 44, 1063 1078. doi:10.3758/s13428-012-0205-1

Etchells, P. Fletcher-Watson, S., Blakemore, S., Chambers , C., Kardefelt-Winther , D., Mills, K., . . . Pfeifer, J. (2017, January 6). Screen time guidelines need to be built on evidence, not hype. The Guardian. Retrieved from https://www.theguardian.com/science/head-quarters/2017/jan/06/screen-timeguidelines-need-to-be-built-on-evidence-not-hype

Evans, M. A., Shaw, D., \& Bell, M. (2000). Home literacy activities and their influence on early literacy skills. Canadian Journal of Experimental Psychology, 54, 65-75. doi: $10.1037 / \mathrm{h} 0087330$

Farrant, B., \& Zubrick, S. (2011). Early vocabulary development: The importance of joint attention and parent-child book reading. First Language, 32, 343-364. doi:10.1177/0142723711422626

German Federal Ministry of Health. (2016). National Recommendations for Physical Activity and Physical Activity Promotion. Retrieved from https://www.sport.fau.de/files/2015/05/National-Recommendations-for-PhysicalActivity-and-Physical-Activity-Promotion.pdf 
Griffin, E. A, \& Morrison, F. J. (1997). The unique contribution of home literacy environment to differences in early literacy skills. Early Child Development and Care, 127(1), 233-243. doi:10.1080/0300443971270119

Hofferth, S. L. (2010). Home media and children's achievement and behavior. Child Development, 81(5), 1598-1619. doi:10.1111/j.1467-8624.2010.01494.x

Huston, A. C., Wright, J. C., Marquis, J., \& Green, S. B. (1999). How young children spend their time: television and other activities. Developmental Psychology, 35(4), 912-925. doi:10.1037/0012-1649.35.4.912

Kabali, H. K., Irigoyen, M. M., Nunez-Davis, R., Budacki, J. G., Mohanty, S. H., Leister, K. P., \& Bonner, R. L. (2015). Exposure and use of mobile media devices by young children. Pediatrics, 136(6): 1044-1050. doi:10.1542/peds.2015-2151

Kucirkova, N., \& Littleton, K. (2016, February). The digital reading habits of children: A national survey of parents ' perceptions of and practices in relation to children's reading for pleasure with print and digital books. Retrieved from http://booktrustadmin.artlogic.net/usr/resources/1407/digital_reading_survey-finalreport-8.2.16.pdf

Lauricella, A. R., Blackwell, C. K., \& Wartella, E. (2017). The “new” technology environment: the role of content and context on learning and development from mobile media. In R. Barr, \& D. N. Linebarger (Eds.) Media exposure during infancy and early childhood: The effects of content and context on learning and development (pp. 1-24). doi:10.1007/978-3-319-45102-2

Lauricella, A. R., Wartella, E., \& Rideout, V. J. (2015). Young children's screen time: The complex role of parent and child factors. Journal of Applied Developmental Psychology, 36, 11-17. doi:10.1016/j.appdev.2014.12.001 
Lavigne, H. J., Hanson, K. G., \& Anderson, D. R. (2015). The influence of television coviewing on parent language directed at toddlers. Journal of Applied Developmental Psychology, 36, 1-10. doi:10.1016/j.appdev.2014.11.004

Li, C., Mendoza, M., \& Milanaik, R. (2017). Touchscreen device usage in infants and toddlers and its correlations with cognitive development. Pediatrics \& Health Research, 2(1), 1-6. doi:10.21767/2574-2817.100013

Liebeskind, K. G., Piotrowski, J. T., Lapierre, M. A., \& Linebarger, D. L. (2014). The home literacy environment: Exploring how media and parent-child interactions are associated with children's language production. Journal of Early Childhood Literacy, 14(4), 482-509. doi:10.1177/1468798413512850

Lovato, S. B., \& Waxman, S. R. (2016). Young children learning from touch screens: Taking a wider view. Frontiers in Psychology, 7(1078), 1-6. doi:10.3389/fpsyg.2016.01078

Ninio, A. (1983). Joint book reading as a multiple vocabulary acquisition device. Developmental Psychology, 19(3), 445-451. doi:10.1037/0012-1649.19.3.445

Northwestern University in Qatar. (2017). Media use in the Middle East 2017. Retrieved from http://www.mideastmedia.org/survey/2017/overview/

Palmer, S., House, R., Coombes, S., Alexander, R., Layard , L., Greenfield, B. S., . . . Whitebread, D. (2016, December 25). Screen-based lifestyle harms children's health. The Guardian. Retrieved from https://www.theguardian.com/education/2016/dec/25/screen-based-lifestyle-harmshealth-of-children

Payne, A. C., Whitehurst, G. J., \& Angell, A. L. (1994). The role of home literacy environment in the development of language ability in preschool children from lowincome families. Early Childhood Research Quarterly, 9(3-4), 427-440. doi:10.1016/0885-2006(94)90018-3 
Piotrowski, J., T. (2017). The parental media mediation context of young children's media use. In R. Barr, \& D. N. Linebarger (Eds.) Media exposure during infancy and early childhood: The effects of content and context on learning and development (pp. 205220). doi:10.1007/978-3-319-45102-2

Przybylski, A. K. \& Weinstein, N. (2017). A large-scale test of the Goldilocks Hypothesis: Quantifying the relations between digital screens and the mental well-being of adolescents. Psychological Science, 28(2), 204-215, doi:10.1177/0956797616678438.

Rice, M. L., Huston, A. C., Truglio, R., \& Wright, J. C. (1990). Words from "Sesame Street”: Learning vocabulary while viewing. Developmental Psychology, 26(3), 421-428. doi:10.1037/0012-1649.26.3.421

Rideout, V. (2011, October 25). Zero to eight: Children's media use in America. San Francisco, CA: Common Sense Media. Retrieved from https://www.commonsensemedia.org/file/zerotoeightfinal2011pdf-0/download Rideout, V. (2013, October 28). Zero to eight: Children's media use in America 2013. San Francisco, CA: Common Sense Media. Retrieved from https://www.commonsensemedia.org/research/zero-to-eight-childrens-media-use-inamerica-2013

Rideout, V. (2017). The Common Sense census: Media use by kids age zero to eight. San Francisco, CA: Common Sense Media. Retrieved from https://www.commonsensemedia.org/sites/default/files/uploads/research/csm_zerotoeigh t_fullreport_release_2.pdf

Rodriguez, E. T., Tamis-LeMonda, C. S., Spellmann, M. E., Pan, B. A., Raikes, H., LugoGil, J., \& Luze, G. (2009). The formative role of home literacy experiences across the first three years of life in children from low-income families. Journal of Applied Developmental Psychology, 30(6), 677-694. doi:10.1016/j.appdev.2009.01.003 
Roseberry, S., Hirsh-Pasek, K., Parish-Morris, J., \& Golinkoff, R. M. (2009). Live action: Can young children learn verbs from video? Child Development, 80(5), 1360-1375. doi:10.1111/j.1467-8624.2009.01338.x

Saudi Council of Economic and Development Affairs. (2016). Vision 2030. Retrieved from http://vision2030.gov.sa/en

Saudi General Authority for Statistics. (2013). Household expenditure and income survey. Retrieved from https://www.stats.gov.sa/en/37

Saudi General Authority for Statistics. (2016). Demographic survey 2016. Retrieved from https://www.stats.gov.sa/en/4522

Saudi National Center for Public Opinion Polls. (2017a). A summary of poll results on Saudi children's use of smart devices and electronic games. Retrieved from https://www.ncpop.org.sa/Questionnaire/Details/1

Saudi National Center for Public Opinion Polls. (2017b). A summary of poll results on Saudis' attitudes toward book reading. Retrieved from https://www.ncpop.org.sa/Questionnaire/Details/4

Seo, H., \& Lee, C. S. (2017). Emotion matters: What happens between young children and parents in a touchscreen world. International Journal of Communication, 11, 561580. Retrieved from http://ijoc.org/index.php/ijoc/article/viewFile/4233/1919

Stiles, J. (2000). Neural plasticity and cognitive development. Developmental Neuropsychology, 18(2), 237-272. doi:10.1207/S15326942DN1802_5

Tomopoulos, S., Dreyer, B. P., Berkule, S., Fierman, A. H., Brockmeyer, C., \& Mendelsohn, A. L. (2010). Infant media exposure and toddler development. Archives of Pediatrics \& Adolescent Medicine, 164(12), 1105-1111. doi:10.1001/archpediatrics.2010.235 Tomopoulos, S., Valdez, P. T., Dreyer, B. P., Fierman, A. H., Berkule, S. B., Kuhn, M., \& Mendelsohn, A. L. (2007). Is exposure to media intended for preschool children 
associated with less parent-child shared reading aloud and teaching activities? Ambulatory Pediatrics, 7(1), 18-24. doi:10.1016/j.ambp.2006.10.005

Turner Broadcasting System International. (2016, March 7). Turner reveals significant findings in kids compass study. Retrieved from http://www.turner.com/node/7707/pdf UK Parliament (2018). Impact of social media and screen-use on young people's health inquiry - publications. Retrieved from https://www.parliament.uk/business/committees/committees-a-z/commonsselect/science-and-technology-committee/inquiries/parliament-2017/impact-of-socialmedia-young-people-17-19/publications/

Vandewater, E. A, Bickham, D. S., \& Lee, J. H. (2006). Time well spent? Relating television use to children's free-time activities. Pediatrics, 117(2), e181-e191. doi:10.1542/peds.2005-0812

Wartella E., Rideout, V., Lauricella, A. R., \& Connell, S. L. (2014, June). Parenting in the age of digital technology: A national survey (Revised). Center on Media and Human Development, School of Communication, Northwestern University. Retrieved from http://cmhd.northwestern.edu/wpcontent/uploads/2015/06/ParentingAgeDigitalTechnology.REVISED.FINAL_.2014.p df

Whitehurst, G. J., \& Lonigan, C. J. (1998). Child development and emergent literacy. Child Development, 69(3), 848-872. doi:10.1111/j.1467-8624.1998.tb06247.x 